\title{
Sistem Pendukung Keputusan Pemilihan Pupuk Untuk Tanaman Padi Menggunakan Metode Fuzzy
}

\author{
Erwin Hermawan ${ }^{1}$, Rudi Hariyanto ${ }^{2}$, Sultoni ${ }^{3}$
}

\begin{abstract}
Subsidized fertilizer requirement continues to peningkatanmeskipun agricultural land is getting narrower, making farmers have difficulty in getting the fertilizer directly influence the productivity of rice into the problems of the farmers. So with the information system provides ease of fertilizer that will come in a computerized decision-making. Decision support system is needed to gain the knowledge expertise of the experts in the diagnosis of rice needs, while the fuzzy inference Mamdani used for processing in order to obtain knowledge of the consequences or conclusions.
\end{abstract}

Intisari- Kebutuhan pupuk bersubsidi terus mengalami peningkatanmeskipun lahan pertanian semakin sempit, membuat petani mengalami kesulitan dalam hal mendapatkan pupuk yang berpengaruh langsung terhadap produktivitas padi menjadi persoalan para petani. Sehingga dengan adanya sebuah sistem informasi ini memberikan kemudahan pemakaian pupuk yang akan datang secara komputerisasi dalam pengambilan keputusan. Sistem pendukung keputusan diperlukan untuk mendapatkan pengetahuan kepakaran dari ahlinya dalam diagnosa kebutuhan padi, sedangkan inferensi fuzzy Mamdani digunakan untuk pengolahan pengetahuan agar diperoleh konsekuensi atau kesimpulan.

Kata Kunci- Pupuk, Padi, Fuzzy, Sistem Pendukung Keputusan

\section{PENDAHULUAN}

\section{A. Latar Belakang}

Kebutuhan pupuk bersubsidi terus mengalami peningkatan meskipun lahan pertanian semakin sempit, membuat para petani mengalami kesulitan dalam hal mendapatkan pupuk yang berpengaruh langsung terhadap produktivitas padi menjadi persoalan para petani. Permasalahan rumit yang dipengaruhi oleh berbagai faktor dan penyelesaiannya melibatkan semua kemampuan pakar, termasuk intuisi yang dimiliki oleh pakar[1].

Pada penelitian ini penulis memfokuskan untuk menganalisa kebutuhan pupuk bersubsidi pada tanaman padi di setiap tanamnya dengan memanfaatkan teknologi informasi[2].

\footnotetext{
${ }^{1}$ Mahasiswa, Jurusan Teknik Informatika Fakultas Teknologi Informasi Universitas Merdeka Pasuruan, Jalan Ir. H. Juanda No 68 Pasuruan INDONESIA $($ e-mail: Hermawane08@gmail.com)

2,3 Dosen, Jurusan Teknik Informatika Fakultas Teknologi Informasi Universitas Merdeka Pasuruan, Jalan Ir. H. Juanda No 68 Pasuruan INDONESIA (e-mail: Rudihariy4nto@gmail.com
}

Sehingga diharapkan dengan adanya sebuah sistem pendukung keputusan memberikan kemudahan informasi tentang kebutuhan pupuk agar kelompok tani tidak kekurangan atau kelebihan dalam pemakaian pupuk di setiap musim tanam dengan menggunakan Logika fuzzy. Logika fuzzy telah menjadi area riset yang mengagumkan karena kemampuannya dalam menjembatani bahasa mesin yang serba presisi dengan bahasa manusia yang cenderung tidak presisi serta menekankan pada makna atau arti[3]. Bisa dibayangkan bahwa sistem fuzzy adalah sebuah mesin penerjemah bahasa manusia sehingga bisa dimengerti oleh bahasa mesin dan juga sebaliknya[4].

\section{METODOLOGI PENELITIAN}

Distribusi pupuk mestinya mengetahui kebutuhan pupuk bersubsidi yang dibutuhkan setiap kelompok tani, agar kelompok tani tidak kekurangan atau pun kelebihan memberikan pupuk di setiap musim tanam untuk mendapatkan hasil panen yang baik, apabila di dukung dengan perkembangan teknologi informasi dengan menggunakan metode fuzyy untuk memberikan informasi tentang kebutuhan seperti kondisi tanah, masa tanam serta iklim.

\section{A. Pengertian Fuzzy}

Logika fuzzy merupakan generalisasi dari logika klasik yang hanya memiliki dua nilai keanggotaan, yaitu 0 dan 1. Dalam logika fuzzy, nilai kebenaran suatu pernyataan berkisar dari sepenuhnya benar, sampai dengan sepenuhnya salah. Dengan teori himpunan fuzzy, suatu objek dapat menjadi anggota dari banyak himpunan dengan derajat keanggotaan yang berbeda dalam masing-masing himpunan. Konsep ini berbeda dengan himpunan klasik (crisp). Teori himpunan klasik tergantung pada logika dua nilai (two valued logic) untuk menentukan apakah sebuah objek merupakan suatu anggota himpunan atau bukan

B. Himpunan Fuzz

Himpunan fuzzy memiliki 2 atribut, yaitu [2]:

1. Linguistik, yaitu penamaan suatu grup yang mewakili suatu keadaan atau kondisi tertentu dengan menggunakan bahasa alami, seperti : Muda, Tua, Parobaya.

2. Numeris, yaitu suatu nilai (angka) yang menunjukkan ukuran dari suatu variabel seperti : 40, 25, 50.

Ada beberapa hal yang perlu diketahui dalam memahami sistem fuzzy, yaitu : 
1. Variabel Fuzzy

Variabel fuzzy merupakan variabel yang akan dibahas dalam suatu sistem fuzzy. Contoh : umur, temperatur, permintaan.

2. Himpunan Fuzzy

Himpunan fuzzy merupakan suatu grup yang mewakili suatukondisi atau keadaan tertentu dalam suatu variabel fuzzy.

\section{Logika Fuzzy}

Logika fuzzy digunakan untuk mengantisipasi hal tersebut dalam pemilihan pupuk bersudsidi. Pemilihan jenis pupuk dapat masuk dalam 2 himpunan yang berbeda, organik dan urea, urea dan SP36, dan sebagainya. Seberapa besar eksistensinya dalam himpunan tersebut dapat dilihat pada nilai keanggotaannya. Dalam himpunan fuzzy, himpunan pemilihan jenis pupuk organik dan urea, urea dan SP36 dapat digambarkan sebagai berikut:

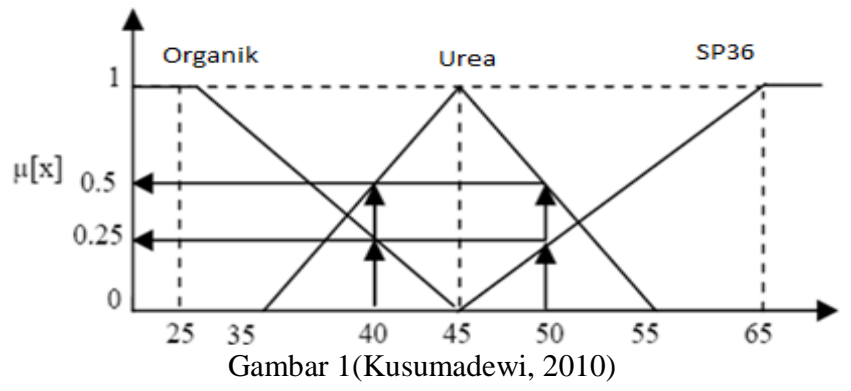

Pada gambar 1di atas, dapat dilihat bahwa :

1. Musim tanam yang berumur 40 hari, termasuk dalam himpunan organik dengan Urea [40] = 0,25 ; namun dia juga termasuk dalam himpunan Urea dengan $\mu \mathrm{Urea}[40]=0,5$.

2. Masa tanam yang berumur 50 hari, termasuk dalam himpunan SP36 dengan $\mu$ sp36[50] $=0,25$; namun juga termasuk dalam himpunan Urea dengan $\mu \mathrm{Urea}[50]=0,5$.

Linguistik, yaitu penamaan suatu grup yang mewakili suatu keadaan atau kondisi tertentu dengan menggunakan bahasa alami, seperti : organik, Urea, Sp36.

\section{RANCANGAN PROGRAM}

Pada aplikasi ini diperlukan beberapa tahapan perancangan sistem yang meliputi beberapa proses yaitu DFD (Data Flow Diagram) dan ERD (Entity Relationsip Diagram) yang diantaranya sebagai berikut:

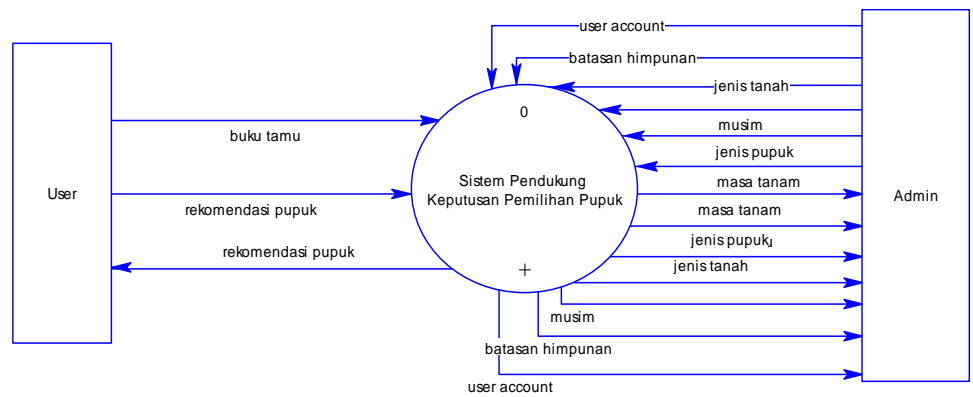

Gambar 2 DFD level 0

Ada dua entitas luar yang berhubungan dengan sistem Admin dan User. dalam pemilihan pupuk memperoleh data-data master yang meliputi data buku tamu, data user account, data musim, data jenis tanah, data jenis pupuk, masa tanam data dan data batas himpunan memberikan keluaran sistem kepada entitas user berupa input buku tamu, rekomendasi pupuk yang sesuai dengan kriteria yang telah di inputkan oleh entitas user.

\section{A. DFD level 1}

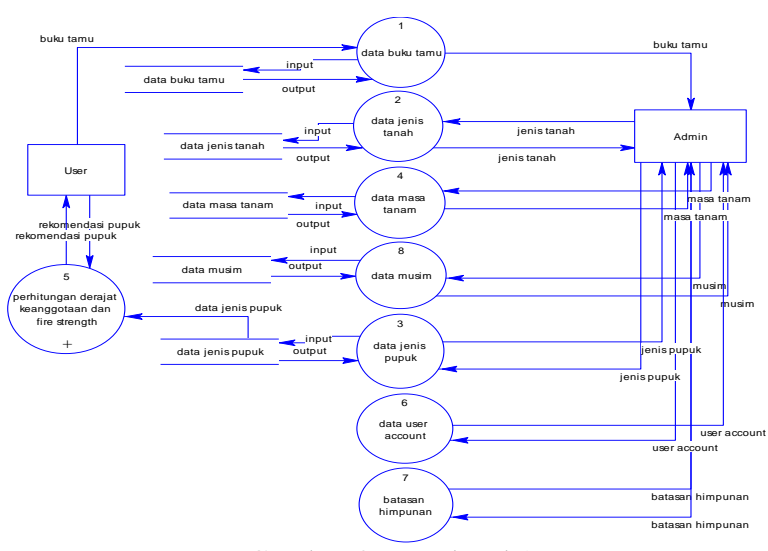

Gambar 3 DFD level 1

Dalam proses DFD level 1 ini menjelaskan tentang alur penyimpanan data kedalam tapel yang tertera di gambar 3 yang terdiri dari:

1. Pada proses olah data buku tamu,

2. Pada proses data jenis tanah

3. Pada proses data masa tanam

4. Pada proses data musim,

5. Pada proses olah data user account

6. Pada proses olah data batas himpunan,

7. Pada proses penghitungan derajat keanggotaan dan firestrength ini membutuhkan data pupuk

Setelah proses penghitungan derajat keanggotaan dan firestrength selesai, maka akan dicari pupuk yang akan direkomendasikan 


\section{B. DFD level 2}

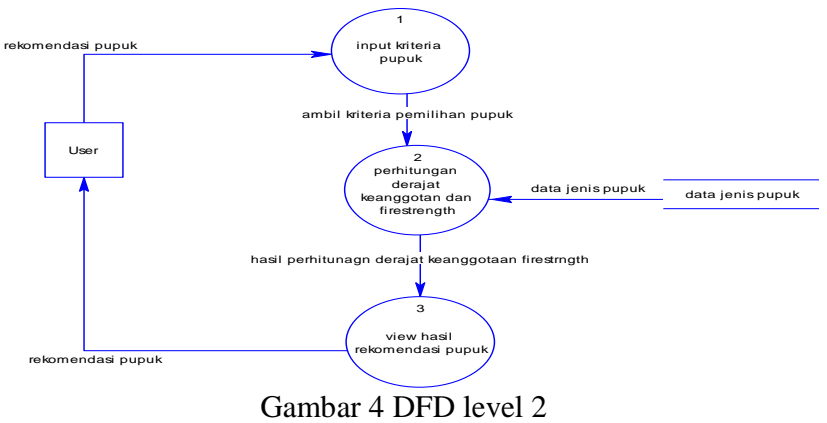

DFD level 2 proses perhitungan derajat keanggotaan merupakan penjabaran yang lebih detail dari proses perhitungan derajat keanggotaan dan firestrength. Pada proses ini terdiri dari tiga proses yaitu input kriteria pupuk, perhitungan derajat keanggotaan dan firestrength dan view hasil rekomendasi pupuk

\section{IMPLEMENTASI}

\section{A. Tampilan Rekomendasi Pupuk}

Sistem pendukung keputusan pemilihan pupuk dapat diakses oleh dua tipe user yaitu admin dan user biasa. Tampilan rekomendasi digunakan untuk mendapatkan rekomendasi pupuk sesuai dengan kriteria yang dimasukkan oleh admin. Tampilan rekomendasi admin berisikan inputan kriteria-kriteria pupuk yang akan dipilih meliputi masa tanam, musim, dan $\mathrm{pH}$ tanah dan selanjutnya akan dilakukan proses query untuk mencari pupuk yang paling sesuai dengan kriteria yang di inputkan.

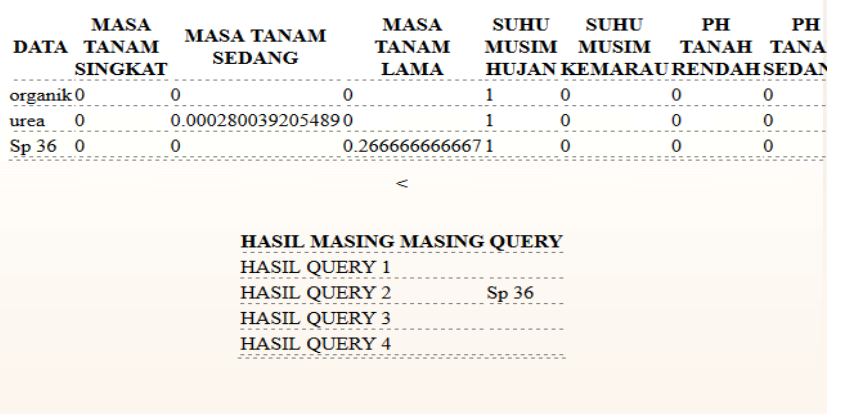

Gambar 5 Tampilan Rekomendasi Pupuk

\section{PENUTUP}

\section{A. Kesimpulan}

Berdasarkan hasil pengujian dan analisis maka dapat diambil beberapa kesimpulan sebagai berikut:

1. Metode fuzzy yang mampu memberikan rekomendasi pemilihan pupuk sesuai dengan kriteria kemudian memberikan urutan pupuk yang lebih sesuai dengan nilai firestrength antara 0-1 dimana nilai 0 merupakan pupuk yang tidak direkomendasikan untuk dipilih dan nilai 1 merupakan pupuk yang direkomendasikan untuk dipilih.
2. Metode fuzzy mempunyai keakuratan data yang tepat untuk sistem pendukung keputusan pemilihan pupuk yang mampu memberikan rekomendasi nama pupuk yang sesuai dengan kondisi tanah dan cuaca.

B. Saran

Sistem pada penelitian ini masih memerlukan pengembangan, untuk itu penulis memberikan beberapa saran sebagai berikut:

1. Desain setiap tampilan halaman masih sangat sederhana sehingga disarankan untuk pengembangan lebih lanjut dari aplikasi diperlukan untuk menambah fitur-fitur yang dapat dilakukan oleh sistem.

2. Perlu adanya metode baru untuk menangani permasalahan selain dengan multi kriteria juga dapat menangani permasalahan dengan multi alternatif.

3. Dalam sistem ini dapat ditambahkan lagi kriteria yang lebih banyak jenis pupuk. Dengan menambahkan beberapa jenis pupuk sehingga petani bisa milih pupuk dengan mudah.

4. Perlu dibuat adanya sistem backup database SPK sehingga jika data SPK rusak dapat dikembalikan lagi seperti semula

\section{Ucapan Terima Kasih}

Terima kasih disampaikan penulis kepada dosen pembimbing di Jurusan Teknik Informatika Universitas Merdeka Pasuruan sehingga penelitian ini selesai dilaksanakan, serta kepada Tim Reviewer Jointecs yang telah melakukan semua perbaikan dalam revisi hingga akhirnya artikel ilmiah ini dapat terpublikasi.

\section{Referensi}

[1] Ferry Trisulistyo, \& Fiftin Novianto (2014). Sistem Pendukung Keputusan Untuk Mendiagnosa Penyakit Hepatitis Dengan Metode Fuzzy Tsukamoto Jurnal Sarjana Teknik Informatika (Nomor 2 tahun 2014)

[2] 2010. Aplikasi Logika Fuzzy untuk Pendukung Keputusan, Kusumadewi., \& Hari. Graha Ilmu, Yogyakarta.

[3] Juliansyah, \& Andrian (2015). Penerapan Metode Fuzzy Tsukamoto Untuk Memprediksi Hasil Produksi Kelapa Sawit. Medan : STMIK Budidarma.

[4] 2004. Pengambilan Keputusan Kriteria Majemuk, Marimin Grasindo, Jakarta. 